\title{
OBSERVATIONS ON WILD RATS IN ENGLAND, WITH AN ACCOUNT OF THEIR ECTO- AND ENDOPARASITES.
}

\author{
Reported by ANDREW BALFOUR, C.B., C.M.G., M.D., B.Sc. \\ Director-in-Chief, Wellcome Bureau of Scientific Research, London.
}

(With Plates XXIII and XXIV, 1 Text-figure and 2 Charts.)

\section{CONTENTS.}

Introduction . . . 282

1. Bacteriological examination of rats $\quad . \quad . \quad . \quad . \quad . \quad 285$

2. Determination of parasites in rats . . . . . . . 288

Collection and Technique . $\quad . \quad$. $\quad . \quad$. $\quad . \quad 289$

Ecto-parasites . . . . . . . . . . 290

Helminths . . . . . . . . . . . 290

Intestinal protozoa . . . . . . . . . . 292

Haematozoa . . . . . . . . . 292

3. Incidence of Leptospira icterohaemorrhagiae and mechanism of its
transmission.
.

Technique . $. \quad . \quad . \quad . \quad . \quad . \quad . \quad . \quad . \quad 293$

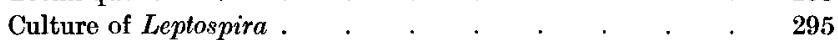

Mechanism of transmission . . . . . . . . 295

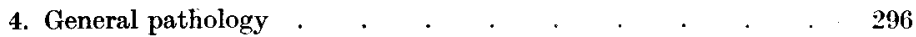

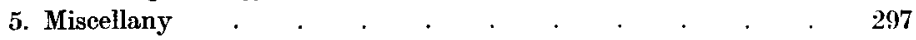

Summary . . . . . . . . . . . . . 297

References . . . . . . . . . . 297

INTRODUCTION.

IT is generally recognised that the measures at present in vogue for the reduction of the rat population are far from satisfactory. A great deal can no doubt be done in the way of lessening the numbers of these destructive and dangerous rodents by poison, bacterial viruses, trapping, the use of natural enemies and so forth, but the rat is so prolific that the losses inflicted by these means are soon made good. The Rodier system attacks the problem from a somewhat different aspect, inasmuch as it is primarily a method of interference with the reproductive life of the rat. Both sexes are trapped, the females destroyed and the males liberated. The relative number of males to females is thereby altered, with the result that the males wage warfare amongst each other, many being killed, while the female also frequently perishes in the struggle for possession.

It would seem that in certain places and under certain conditions the Rodier system works well but it appears more adapted for use in limited areas. 
A suggestion has already been made to the effect that its value might be determined by experimental work on ship-board but so far nothing has been done in this direction. The method has certain drawbacks. It is not easy to handle wild rats; only a professional rat-catcher or someone with special experience can do so with impunity. Again it is by no means always easy, in the case of young specimens, to determine the sex.

In thinking matters over the idea occurred to one that if only some bacterial agent could be found which would either produce sterility in rats or induce abortion it might be possible to employ it to advantage and in such a way that the male rat might infect the female during the sexual act.

It was clear that in the first place it would probably be difficult to find any such organism which could be safely used and in the second that even if it were forthcoming and proved pathogenic only to the rats there was every likelihood that the rodent would soon develop an immunity against it. Still a research of this nature appeared to offer some possibilities, for it is easy to understand how useful a wholesale interference with the rat's family life, even for a limited period, might be if the rat population were found harbouring B. pestis and there was a danger of an outbreak of human plague.

It appeared, therefore, worth while to set such an enquiry afoot, especially as, during its course, other matters of interest and importance could conveniently be studied.

Eventually a system of team work was evolved with a view to collecting information on the following points:

1. The possibility of obtaining, either from rats themselves or from some outside source, an organism which could be safely used on a large scale for producing sterility or inducing abortion in rats and which could be transmitted from the male to the female rat and possibly also conversely during coitus.

2. The occurrence of rat parasites, including ecto-parasites, helminths, intestinal protozoa and haematozoa.

3. The incidence of Leptospira icterohaemorrhagiae and the mechanism of its transmission.

4. The presence of pathological conditions, apart from those associated with the genito-urinary system, in the rats examined.

5. Any other matters of general interest regarding the rat population as, for example, the relation of the pregnant state to season.

At the outset I wish to point out that personally I have been but little associated with this research work. Indeed, for a large part of the time during which it was being prosecuted I was abroad, but as I initiated it and have been more or less in touch with it throughout it has been considered advisable that I should place the results, such as they are, on record.

The main object of the enquiry was in the hands of Major H. C. Brown who was entrusted with the bacteriological work. Lt-Colonel G. E. F. Stammers performed most of the post-mortem examinations on rats, examined blood films, and kept a record of the findings. 
Rat parasites were studied by Dr A. C. Stevenson and Mr Gerald Dudgeon. Dr Stevenson made the majority of the examinations for intestinal protozoa and determined the incidence of Leptospira infections. Mr Dudgeon carried out a study of the helminths and ecto-parasites. Dr Wenyon, with a view to determining if the rat harboured cultural flagellates other than trypanosomes, examined by culture in $N N N$ medium the blood of a hundred rats, but found the only organism present was Trypanosoma lewisi.

Throughout, our Senior Laboratory Assistant, Mr W. J. Muggleton, rendered valuable aid, arranging for the supply of material and assisting in all branches of the enquiry.

MrH.A. Baylis of the British Museum was good enough to aid Mr Dudgeon in the identification of worms and to advise on certain points connected with them.

In all 478 wild rats were examined, of which 34 were Ratus rattus and the remainder Rattus noriegicus. No conclusion can be drawn from these figures as to the relative proportion of the two species, as the dealers only sold black rats when these were specially wanted, the skins of black rats being of greater value than those of grey rats. It seems also that the black rat is rarely captured save on board ships or at the docks, and this although a higher price is paid the rat-catchers for black rats.

The rodents were for the most part obtained from dealers in London and were London rats, but specimens were also secured from such towns as Bedford, Brighton, Chester, Eastleigh (Hants), Horsham, Liverpool, Luton, Maidstone, Preston, Reading and Sandwich. Occasionally rats from country districts were secured and a few were captured from ships at the London Docks. We were much indebted to Mr G. L. Moore of Maidstone for the kind help he gave us in obtaining country rats.

The period of work covered more than a year. The investigation was started on August 16th, 1920, and, with a month's intermission in August, 1921, ended on December 14th, 1921.

Generally speaking the condition of the rodents was good. As a rule they were well nourished and, beyond showing recent and sometimes septic wounds and the scars of old lesions, rarely exhibited any external sign of injury or deformity.

Every rat was weighed and this gave some idea regarding maturity. So far as female rats went, the almost invariable presence of corpora lutea indicated that we were dealing with adults and it would seem that a minority of immature animals were examined. The weights of male Rattus rattus varied from 75 to 180 grammes and of females from.75 to 225 grammes, no pregnant black rats being found. The heaviest female black rat not showing corpora lutea weighed 118 grammes.

The weight of male Rattus norvegicus ranged from 100 to 510 grammes and of females from 85 to 470 grammes, excluding pregnant animals.

The heaviest female brown rat not showing corpora lutea turned the scale at 170 grammes. 
Of 217 female brown rats examined 32 were found to be pregnant, litters varying from 1 to 12 , the average in 27 cases where an estimate could be made being 7 .

\section{BACTERIOLOGICAL EXAMINATION OF RATS.}

After opening the abdomen, organs from which bacteriological preparations were made and cultures were taken were seared on the surface and incised with sterile instruments under aseptic conditions. At first in the case of female rats cultures were taken in every instance, save when the animal was pregnant, from the upper portion of the vaginal tract or from the uterus and incubated both aerobically and anaerobically.

A number of different organisms, both cocci and bacilli, were isolated which could be grouped according to their sugar reactions. As nothing of any practical interest was found, either by these fermentation tests or by subjecting the organism isolated to serological tests (i.e. organism versus blood serum of host, organism versus serum of other rats or organism versus group high titre serum), this routine was discontinued and attention directed solely to the recovery of organisms from the genital tracts of female rats which exhibited definite pathological changes.

There were only four instances of this kind, three of which were fully examined. One was a case of pus in the Fallopian tubes in a non-pregnant rat, two were cases in which the uterus contained dead foetuses, the fourth an example of extra-uterine gestation.

The protocols of the three cases examined are as follows:

(i) Rat 207. Non-pregnant. Pus of a cheesy character present in the uterus and in both Fallopian tubes.

On aerobic culture from this pus two organisms were found, i.e.: (a) a gramnegative coccus and (b) a gram-positive streptococcus.

Cultures of both these organisms were inoculated together intraperitoneally into an apparently healthy mouse, which died in 24 hours. A blood culture from the heart of this mouse revealed the presence of another organism $(c)$ while the original $(a)$ and $(b)$ were not recovered. Organism $(c)$ was eventually proved to be $B$. enteritidis Gaertner. A culture of this organism before it had been definitely identified was introduced into the vagina of a tame rat on January 21st, 1921. The animal died on February 17th, 1921, and it is interesting to note that the bacillus was recovered not only from the heart-blood but also from the Fallopian tubes. Various other passages were carried out, both in the case of male (preputial infection) and female rats but as the organism was eventually found, as stated, to be a species pathogenic both to man and animals and hence unsafe to use for our purpose, further work with it was abandoned.

Organisms $(a)$ and $(b)$ were inoculated separately intraperitoneally into laboratory mice on February 16th, 1921. No ill effects were produced. On March 16th, 1921, three rats were given a vaginal injection of $(a)$, three rats were given a vaginal injection of $(b)$, three were given a vaginal injection of 
$(a)+(b)$. Two of the rats infected with (b) died on April 3rd from pneumonia. Nothing abnormal was found by the naked eye in their genital tracts which were not further examined. The remainder were kept and watched for two months to see if any sub-acute or chronic malady resulted. Nothing was observed. They were then placed with males.

All three of the rats injected with $(a)$ had healthy litters, on June 5th, 12th and 14th respectively. The third injected with $(b)$, which was placed with a male on two occasions, had a healthy litter on July 20th, 1921. Of those infected with $(a)+(b)$ two had litters on June 5th and the third was obviously pregnant on June 21st.

Hence organisms $(a)$ and $(b)$ were ruled out of court.

(ii) Rat 330. Chloroformed May 10th, 1921, and two dead foetuses found in the uterus.

Aerobic cultures from the uterus resulted in the isolation of $(d)$, a gramnegative coliform bacillus, and (e), a gram-positive coccus.

The vagina of a tame rat was smeared with material from the uterus of Rat 330 on May 11th, 1921, and this animal was placed with a male on May 14th. It had a healthy litter on June 11th, 1921.

Two other tame rats were injected per vaginam with a mixture of a 24 hours growth of $(d)$ and $(e)$ on May 12th. They were placed with males on May 14th and had healthy litters in due course.

Apparently, therefore, neither of these organisms was of the type required.

(iii) Rat 369. Chloroformed June 27th, 1921. Found to have an extrauterine gestation from which cultures were taken. Two organisms were isolated $(f)$, a coliform bacillus, and $(g)$ a gram-positive streptococcus.

Material from cultures of both organisms was introduced into the vaginas of two rats on June 28th, in one case by injection, in the other by smearing. The smearing method was employed as it was thought it might produce slight surface abrasions such as possibly occur during coitus. Both were placed with males on June 30th and both had litters.

Six other white rats were injected per vaginam on July 11th, 1921, with a broth emulsion of $(f)$ and $(g)$ and subsequently placed with males. All were pregnant on July 29 th. In no instance was any ill effect produced as the result of injection.

It therefore appeared clear that organisms $(f)$ and $(g)$ were not of service.

Having failed to obtain in wild rats under natural conditions any organism having the effect desired, attempts were made to infect the genito-urinary tract of tame rats with an organism which it was hoped might prove efficacious either in producing abortion or sterility.

The choice was limited, because care had to be taken that any organism employed should be of such a nature as to obviate any risk of producing serious effects in man or the domestic animals. The ideal would, of course, be one which, while capable of producing the desired effect in wild rats, was incapable of transmission to man or the domestic animals or, if transmitted 
to them, was perfectly harmless, existing in them only as a saprophyte. It was not possible to find any such organism and in any case it was not feasible to employ wild rats for experimental purposes. Hence, as in the previous experiments, recourse was had to laboratory animals.

It was considered best to make a start with Micrococcus catarrhalis as this organism affects mucous membranes, is very unlikely to be transmitted from rats to man and, even if so transmitted, is so mildly pathogenic to human beings and in any case so common in their nasal passages that any fresh source of infection might, it was felt, for practical purposes be disregarded.

Accordingly a strain of $M$. catarrhalis (Gordon) was obtained from the National Collection of Type Cultures, Lister Institute, and cultures of it were used for the purpose of smearing the vaginas of tame rats.

In the first instance the vagina of a tame rat was smeared with a 24 hours culture of this organism. This rat was put with a male a few days later. She did not become pregnant but this may have been due to the experiment being performed at a time which was not the normal breeding season.

In the second case in which this organism was used a 24 hours culture was mixed with one of Staphylococcus albus which had been recently isolated from a case of gleet, and a heavy growth of these organisms was smeared on the walls of the vagina of one white rat which was afterwards put with a male. The former rat had a healthy litter 27 days after the inoculation. The mixed culture was used to see if symbiosis might play any part in pathogenicity.

My attention having been directed to the work of Teacher and Burton on infective abortion in guinea-pigs, I wrote to Dr Teacher and he very kindly supplied me with two strains of the diphtheroid bacillus which he and his co-worker had shown to be the cause of the second epizootic which they reported. The first was due to streptococci, of which pure cultures had not been obtained, so it was not possible to employ these organisms in our investigation.

Although it appeared advisable to test the diphtheroid bacillus abovementioned the outlook regarding its possible value was not very promising. Teacher and Burton were unable to bring about abortion by the introduction of cultures into the vagina and, as a result of their experiments, concluded that in all probability the natural and only route of infection is through the blood stream. They proved that the bacilli have a definite seat of election in the cavity of the yolk-sac.

Sub-cultures were prepared from both the strains supplied by Dr Teacher and 24 hours growths were used for the inoculations.

The vagina of a white rat was smeared with a mixed culture and it was placed with a male.

The female died $2 \frac{1}{2}$ months later without becoming pregnant, the cause of death being abscess of the lung. The failure to conceive was not conclusive as the experiment was not conducted during the normal breeding season. 
In the second instance two female rats showing early signs of pregnancy were used and the walls of the vagina were thoroughly smeared with a 24 hours culture of the two strains of this diphtheroid organism. Both of these rats, however, had healthy full-timed litters thirteen and seventeen days later respectively.

It is fully recognised that these experiments were conducted on a very small scale. This was largely due to the extreme difficulty of procuring tame rats from dealers in London during the earlier part of 1921. The results, however, at any rate with the diphtheroid organism, are in accordance with those obtained by Teacher and Burton (Journal of Pathology and Bacteriology, $\mathrm{xx}, 1915$, p. 14) who found that the introduction of cultures of this organism into the vaginas of guinea pigs were negative.

Although the record of these experiments appears scanty the work itself involved a great deal of time and labour and it is unfortunate that nothing definite resulted from it; still, negative results possess a certain value and it seems desirable to draw attention to the matter in case others, perhaps differently situated, may care to carry out further investigations. It was not possible to conduct the enquiry on as large a scale as we originally contemplated, but the failure to recover any efficient organism from wild rats and the paucity of pathological conditions in the genitalia of these animals militated against the success of the work. It is conceivable that in the tropics conditions are different and that a research on these lines might prove more promising

\section{DETERMINATION OF PARASITES IN RATS.}

This was taken up as a matter of routine although no very novel results were expected, as the field has already been covered by various observers. At the same time, so far as I am aware, no work on precisely the same lines has been undertaken in this country. Shipley, in 1908, published a useful paper on "Rats and their Parasites," in which he gave a list of all the various kinds of parasites found on and in rats but this applied to other parts of the world as well as England.

So far as fleas are concerned the most complete account is that by Bacot, 1919. His paper included two lists, one of all the fleas found on rats up to that date in all parts of the world, the other confined to fleas found on rats in Britain. It will be seen (vide infra) that we found only four of the eighteen species he records. Doubtless this is due in part to the fact that the great majority of our rats came from London and nearly all of them from towns. As Bacot points out, rats are probably the true hosts of only seven or eight of the species he mentions.

Newstead and Evans (1921) determined the species of fleas found on rats in Liverpool and identified Xenopsylla cheopis, Ceratophyllus fasciatus, Leptopsylla musculi, Ceratophyllus londoniensis and Ctenocephalus canis. The firstnamed was found chiefly on ship rats and Leptopsylla musculi was most prevalent on rats from the dock area. We did not find this flea but, on the 
other hand, encountered Ctenophthalmus agyrtes which they did not come across. This is probably because some of our rats came from rural districts, as was the case with those searched by Nuttall, Strickland and Merriman during their investigations in East Anglia.

To Hirst (1914) we owe information regarding the Acari found on the brown rat in Great Britain and the description of a species which was new at the time he wrote.

The only other papers to which allusion need here be made are those by Moll (1917), "Animal Parasites of Rats at Madison, Wisconsin," which considers only ecto-parasites and helminths, and the Presidential Address of Cleland (1918) to the Royal Society of New South Wales in which the author enters fully into the question of rat parasites but which is merely of the nature of a review of the subject.

At the time Shipley wrote little was known about the intestinal protozoa of the rat but of recent years attention has been directed to the matter. We give a list of six parasites of this class which were encountered by us both in black and brown rats. Shipley's list of helminths is now very much out of date, as much work has been done on the worms of rodents in general and of rats in particular, and it will be found that the present investigation has revealed the presence of a new cestode and has been of interest in other directions.

Thestudy of haematozoa has not been very fruitful but has demonstrated the presence of Hepatozoon muris in the leucocytes of the black rat in this country.

Apparently the only work following closely the lines we adopted is that of Splendore, but it deals primarily with parasites of the field vole Pitymis savii Selys. Incidentally he mentions the parasites, ecto-parasites, haematozoa and helminths, which rats share in common with this animal. His observations are of an extensive nature and refer also to bacteria, fungi and intestinal protozoa.

\section{Collection and Technique.}

The rats were for the most part collected from the dealers' shops where they are kept in large cages, each cage containing a number of animals. They had been captured comparatively recently, but as a rule had been in captivity for some hours or even for several days prior to purchase, and were accordingly "sweated." As Newstead and Evans have pointed out in their "Report on Rat Flea Investigation in Liverpool," such sweated rats are apt to lose their fleas, so that it is possible that the number of ecto-parasites, and more especially of fleas, did not quite represent all those originally present on their hosts.

The latter were transferred from the dealers' cages to perforated tin cases, one rat being placed in each tin, and so conveyed to the laboratory where they were chloroformed in the tins and weighed as soon as dead. Any ecto-parasites which had left their hosts in the tins were collected. These proved to be chiefly fleas and were not numerous. Thereafter the fur of the rat was carefully combed with a very fine comb, special attention being paid to the neck region and the point of junction of the limbs with the body on the under-surface of the 
animals. In each case the findings were placed in tubes which were labelled with a number corresponding to that of the host. At a later date the ectoparasites were determined. A post-mortem examination of the rat was then performed. Films were prepared from the heart blood. The alimentary tract and urinary bladder were removed and searched for helminths. Specimens of the intestinal contents were examined for protozoa, any macroscopic abnormalities were noted and, if necessary, portions of the internal organs were taken for section-cutting and staining.

\section{Ecto-Parasitites.}

(i) The following were found:

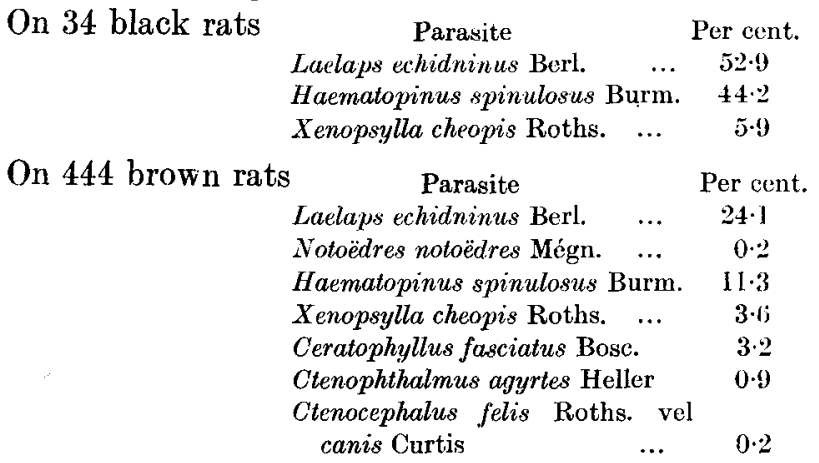

\section{Helminths.}

The following intestinal forms were found:

In 34 black rats

$\begin{array}{ccc}\text { Parasite } & \text { Per cent. } \\ \text { Hymenolepis diminuta } \text { Rud. } & 17 \cdot 6 \\ \Rightarrow \quad \text { nana-fraterna } & \text { Stiles } & 17 \cdot 6 \\ \# \quad \text { longior Baylis } & . . & 32 \cdot 4 \\ \text { Oxyuris obvelata Rud. } & \ldots & 3\end{array}$

In addition Trichosomoides crassicauda Bell was found on three occasions in the urinary bladder but as only a small number of black rats were examined for the presence of this parasite it would serve no purpose to state a percentage.

In 430 brown rats the intestinal worms were as follows:

\begin{tabular}{|c|c|}
\hline Parasite & Per cent. \\
\hline Hymenolepis diminuta Rud. & $28 \cdot 4$ \\
\hline nana-fraterna Stiles & $1 \cdot 2$ \\
\hline longior Baylis ... & $24 \cdot 9$ \\
\hline Heligmosomum braziliense Trav. & $8 \cdot 6$ \\
\hline , $\quad$ vexillatum Hall & $0 \cdot 2$ \\
\hline Viannaia? sp. incert. & $0 \cdot 7$ \\
\hline Capillaria annulosa Dujardin & $0 \cdot 4$ \\
\hline
\end{tabular}

Trichosomoides crassicauda Bell was found in the bladder of 48.3 per cent. of 333 rats examined.

The unidentified ova (av. measurements $75 \mu \times 39 \cdot 7 \mu$ ) of an unknown worm were seen in the intestinal contents on three occasions. As no corre- 
sponding worms were found it is possible that these eggs had been swallowed by the rats and had passed through their bodies unchanged ${ }^{\mathbf{1}}$.

Very often Cysticercus fasciolaria of Taenia crassicollis Rud. of the cat was found encysted in the liver and in one case the eggs of Hepaticola hepatica Bancroft, a nematode first observed by Chaussat in 1850, were found in sections of the liver together with portions of the worm itself (Pl. XXIII, figs. 1 and 2). There is a good account of this parasite of rats by Hall in the Proceedings of the United States National Museum, L, 1916, p. 30.

As a result of this work on worms two papers have already been contributed to the literature, one entitled "Observations on Certain Cestodes of Rats" by H. A. Baylis of the British Museum, the other on the "Occurrence
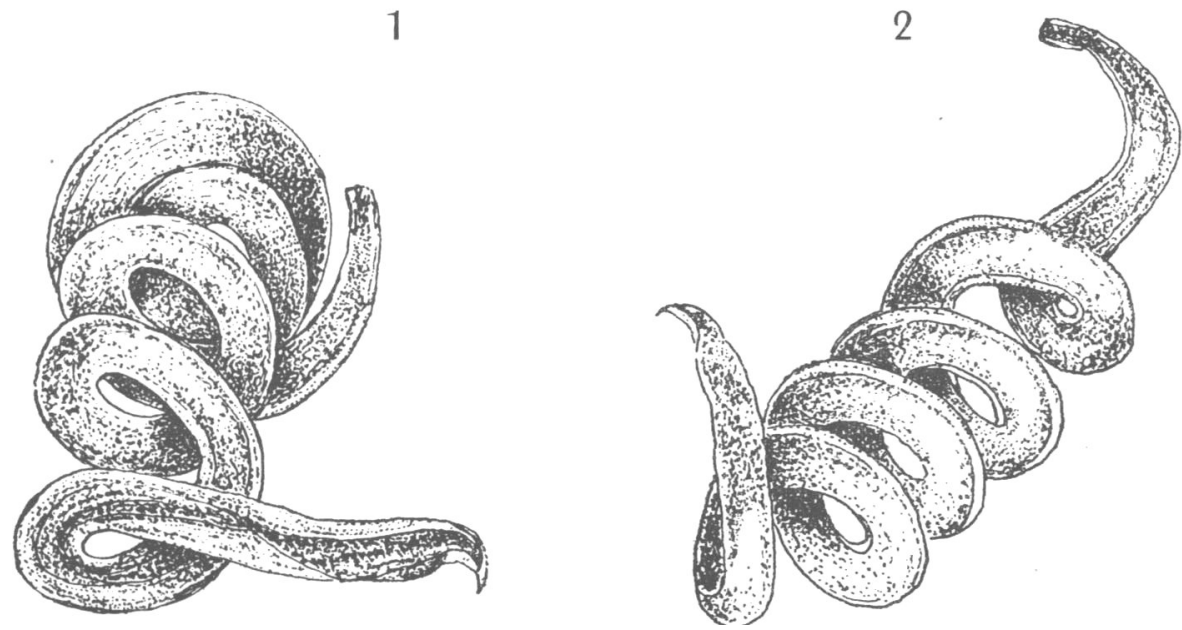

Fig. 1. (1) Intestinal worm of rat found along with Heligmosomum braziliense and possibly a species of Viannaia. Greatly enlarged. Actual length $=3.88 \mathrm{~mm}$.

(2) As above. Actual length $=3 \cdot 25 \mathrm{~mm}$.

of Heligmosomum braziliense Trav. in England," by G. C. Dudgeon. Under the former title the new Hymenolepis longior is fully described and illustrated. Although not stated in the latter paper Heligmosomum braziliense had previously only been found in Brazil and Australia.

In the duodenal mucus of three rats there was found a number of small transparent worms with blackish granulations in their interior, occurring along with Heligmosomum braziliense. These, by reason of their form-corkscrew spiral--and the absence of longitudinal ridges on the cuticle, conformed to the character distinctions of the genus Viannaia, but as no sex organs were seen nor any eggs, it was impossible to place them in any genus. It is possible they may be immature and undescribed forms of $\boldsymbol{H}$. braziliense.

Pl. XXIV, fig. 3 , shows the contrast between $H$.braziliense and the possible Viannaia (Text-fig. 1) as seen in the intestinal mucus.

1 The above suggestion that the eggs had been swallowed is probably erroneous, as further examination of sections has shown the presence of groups of eggs, situated in the crypts of Lieberkühn, high up in the small intestine and in various stages of development. 


\section{Intestinal Protozoa.}

It is only necessary to give a list of those found, with percentage incidence. In 32 black rats:

$\begin{array}{lllc}\text { Parasite } & & \text { Per cent. } \\ \text { Entamoeba muris Grassi } 1882 & \ldots & \ldots & 25 \\ \text { Trichomonas muris Galli-Valerio } & 1910 & 81 \cdot 2 \\ \text { Octomitus intestinalis Grassi } 1882 & \ldots & 6 \cdot 2 \\ \text { Giardia muris Bensen } 1907 & \ldots & \ldots & 6 \cdot 2 \\ \text { Chilomastix bettencourti Fonseca } & 1915 \ldots & 18 \cdot 6 \\ \text { Eimeria falciformis A. Scheider } & 1874 \ldots & 50\end{array}$

In 440 brown rats

\begin{tabular}{llrc}
\multicolumn{1}{c}{ Parasite } & & Per cent. \\
Entamoeba muris Grassi 1882 & $\ldots$ & $\ldots$ & $15 \cdot 7$ \\
Trichomonas muris Galli-Valerio & 1910 & $12 \cdot 7$ \\
Octomitus intestinalis Grassi 1882 & $\ldots$ & $1 \cdot 7$ \\
Giardia muris Bensen 1907 & $\ldots$ & $\ldots$ & $6 \cdot 8$ \\
Chilomastix bettencourti Fonseca & $1915 \ldots$ & $1 \cdot 8$ \\
Eimeria falciformis A. Scheider & $1874 \ldots$ & 21
\end{tabular}

On two occasions in the black rat cysts of the $E$. culi type were noted. They are possibly the same as those found by Brug. The presence of Blastocystis was noted not infrequently. Some of the above findings have already been recorded in a paper by Stevenson (vide infra).

\begin{tabular}{|c|c|c|c|}
\hline \multicolumn{4}{|c|}{ Hafmatozoa. } \\
\hline Parasite & & $\begin{array}{c}\text { In } 34 \text { black rats } \\
\text { per cent. }\end{array}$ & $\begin{array}{l}\text { In } 444 \text { brown rats } \\
\text { per cent. }\end{array}$ \\
\hline Trypanosoma lewisi Evans & $\cdots$ & $38 \cdot 2$ & 19 \\
\hline Hepatozoon muris Balfour & $\ldots$ & $5 \cdot 9$ & $10 \cdot 8$ \\
\hline Grahamella joyeuxi Brumpt & 913 & - & $0 \cdot 2$ \\
\hline
\end{tabular}

Dividing forms of $T$. lewisi, indicating an early stage of infection, were twice seen in the heart's blood, and a peculiar feature of the majority of trypanosomes found in one rat was the presence of a small granule surrounded by a clear halo in the cytoplasm-adjacent and posterior to the nucleus. According to Wenyon this granule has not previously been noted in T. lewisi, and it seems worthy of record owing to the constancy of its occurrence in this particular instance. In some cases it was elongated, in others double, so it is possible that this is evidence of the division of the granule by fission. However, no opinion can be expressed regarding its true nature. Stained with Leishman it appeared of a lilac colour, very different from the deep red of the kinetonucleus.

An illustrated note on "Haemogregarines in Black Rats" was published by G. E. F. Stammers. This, it is believed, was the first record of the occurrence of haemogregarines in the leucocytes of the black rat in Europe. 

OF ITS TRANSMISSION.

The publication in 1919 of the very complete monograph by Martin and Pettit entitled Spirochétose Ictérohémorragique has rendered any detailed consideration of the literature superfluous. There have, however, been some important papers since the appearance of the French work and to these, when necessary, attention will be directed.

\section{Techaique.}

At the autopsies when urine was present in the bladders of the rats it was examined by the dark field method. In addition it was customary to make smears from the kidney which were stained by Giemsa, while in a few of the earlier cases portions of the kidney were stained in block by the Levaditi method. As a further confirmatory test on a good many occasions the urine or an emulsion of kidney and liver tissue were inoculated into guinea pigs intraperitoneally.

The results of these procedures were on the whole confirmatory though, as other observers have found, a certain proportion of guinea pigs cannot be infected, either because they are insusceptible or possibly because the particular strain of leptospira possesses no pathogenicity for these animals. In cases where infected urine was employed it is conceivable, as suggested by Uhlenhuth and Zuelzer, that the urine had itself exerted a detrimental effect on the organism, rendering it innocuous. These observers believe that the acidity of urine is a potent factor in weakening or killing the leptospira. There must also be considered the view put forward by Foulerton that infection with Leptospira icterohaemorrhagiae can only be definitely determined by guinea pig inoculation. On these grounds he rejects the work of Coles at Bournemouth in 1918. This is doubtless true, but, as pointed out, the inoculation test is by no means a certain one and, as the presence of a leptospira-like organism can after sufficient experience readily be detected in tissue emulsion and in the urine by the dark field method and also in stained smears and sections, and as no other organism morphologically similar is known to infect rats in this country, it is reasonable to assume that in the case of positive findings by these various methods one is actually dealing with Leptospira icterohaemorrhagiae. If positive infections with guinea pigs are alone accepted as a criterion of infection there can be no doubt that, for the reasons above stated, cases will be missed.

A record of part of this work has already been published by A. C. Stevenson in a paper entitled "The Incidence of a Leptospira in the Kidneys and of Parasites in the Intestines of One Hundred Wild Rats examined in England." He showed by a comparison of kidney smears and kidney sections that, in the hands of an experienced observer, the smear method sufficed to reveal the presence of leptospira. 
The general findings were as follows:

The urine of 154 brown rats was examined and leptospira-like organisms were seen on twenty-one occasions, i.e. in $13 \cdot 6$ per cent. of the cases. The urine of black rats proved invariably negative but it was only possible to make the examination in fifteen instances.

The kidney examinations by smears and sections from brown rats yielded positive results in $22 \cdot 6$ per cent. The few black rats examined in this way were negative.

At first a systematic series of inoculations of guinea pigs either with urine or kidney and liver emulsion was carried out. Twenty-one animals in all were inoculated, two with urine and nineteen with tissue emulsion. The former remained unaffected, of the latter three became infected and died of typical spirochaetal jaundice.

Thereafter it was decided to inoculate guinea pigs only from rats in which leptospira had been found. Five such experiments were conducted, in three cases infected urine being used and in two leptospira-containing tissue emulsion. Of the urine cases one was positive and it is interesting to note that another guinea pig inoculated in a similar manner and with an equal dose of the same urine remained uninfected.

Of the emulsion cases one was positive and here again two guinea pigs were used, one of which yielded a negative result.

These findings tend to show that there may be a true insusceptibility to infection.

Of a total of 40 rats yielding positive results by the inoculation method and by the examination of smears and sections from the kidney, four were from places outside London, two being from Maidstone, one from Colchester and one from Preston. In this connection Dr Stevenson's statement in his paper above quoted, to the effect that a positive rat came from Cheshire, is incorrect. He should have stated Lancashire - the rat to which reference is made being that from Preston.

The investigations of Foulerton on London rats indicated that there was a distinct seasonal incidence. In rats examined by the inoculation method between July 12th and November 18th, 1918, he obtained positive results only during November, a failure which may have been due to guinea pig insusceptibility. In our observations there is also some indication of a limitation according to season in cases where infection was proved by inoculation, the months in which positive results were obtained being October, November and December. On the other hand, if the whole series of positive cases is considered there is evidence that rats harbour leptospira throughout the year.

One record is of special interest as showing how a guinea pig may perhaps act as a carrier without exhibiting any visible signs of disease beyond a transient rise of temperature and thus coming into line with the rat itself.

Rat 215, Rattus norvegicus, female, non-pregnant, weighing 230 grammes, from Cheapside, was found by dark field examination to have leptospira in the urine. 
1 c.c. of the urine was inoculated intraperitoneally into a guinea pig on January 19th, 1921.

A rise of temperature was noted on January 24 th but no other sign of illness was at any time observed. The temperature fell to normal on January 29th and remained normal till February 9 th when there was a further slight rise lasting one day.

From this time onwards until the end of the period of observation, i.e. 50 days from date of inoculation, the animal remained apparently in perfect health. It was killed on March 11th and the autopsy showed no signs of infectious jaundice.

A saline emulsion of the liver, lung, kidney and suprarenal was inoculated intraperitoneally on March 11th into another pig, which died on March 22nd with typical post-mortem appearances of the disease after exhibiting the usual clinical symptoms.

There appears to have been no chance of the first guinea pig having become infected subsequent to the inoculation as it was kept in a separate cage, this being the rule in the case of all the experimental animals save those inoculated from one source. It was the custom to keep those together in one cage and it is interesting to note that if one of these developed the disease it did not transmit infection to any of the others.

\section{Culture of Letrospira.}

For this purpose Wenyon's modification of Noguchi's blood-agar medium was utilised.

Culture was employed chiefly for the purpose of maintaining the strain and thus saving guinea pigs. The leptospira grew vigorously in this medium. In 48 hours at $30^{\circ} \mathrm{C}$. the cultures, taken from the heart blood and organs of infected guinea pigs, were found teeming with the organisms, which remained viable from two to three months. In early culture virulence for guinea pigs was fully maintained but after repeated subculture, although a characteristic febrile reaction and the appearance of jaundice followed inoculation, the animals survived.

Even after a year's subculture at weekly or monthly intervals these definite symptoms were forthcoming but, as stated, there was undoubtedly attenuation of the virus.

Nothing not already recorded by other observers was noted as regards the morphology of the cultural forms.

\section{Mechanism of Transmission.}

The experiments as regards transmission can be divided into the following groups:

1. Feeding experiments

(a) With natural food infected with leptospira-containing material from guinea pigs dead of the disease. Urine and organ emulsions were used (3 cases). 
(b) With similar infective material administered by the catheter (7 cases).

2. Inunction experiments

(a) With infective material through the skin without shaving the hair (4 cases).

(b) With infective material through the shaved skin (1 case).

These experiments were discontinued when the results of the work of Uhlenhuth and Zuelzer (1921) became available, as the hypothesis they advanced appeared a very reasonable one which was capable of explaining the vagaries of the disease. At the same time there are certain lines of investigation which have not yet been followed and it may be possible to undertake them at a later date.

It is scarcely necessary to give the results of this part of the investigation in detail. Only two positive results were obtained, both in catheter-fed animals. Each of these animals was given 1 c.c. of a saline suspension of the macerated kidneys of two guinea pigs which had died of infectious jaundice. One of the

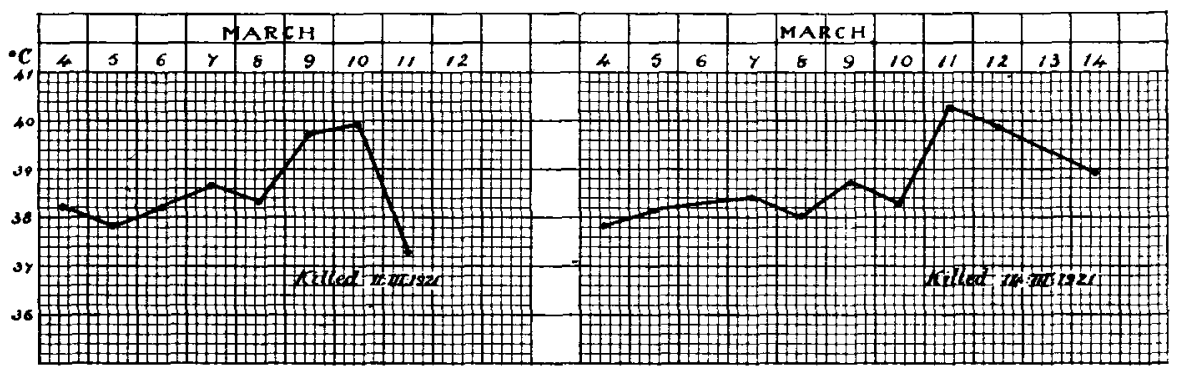

Chart 1. Eight-day temperature chart of guinea pig $79(\%)$, fed by catheter with emulsion of organs of infected guinea pig. Autopsy : typical of spirochaetal jaundice.

Chart 2. Eleven-day temperature chart of guinea pig $81\left({ }^{*}\right)$, fed by catheter with emulsion of organs of infected guinea pig. Autopsy: typical.

catheter-fed animals was killed 7 days, the other 10 days after injection, and both showed typical post-mortem appearances of the disease. During life both exhibited jaundice and an elevation of temperature (Charts 1 and 2) and in one case there was a characteristic and sudden fall coinciding with the termination of the malady (Chart 1). Had the animal not been killed it would have died within a short time.

\section{GENERAL PATHOLOGY.}

Pathological conditions, apart from those associated with helminthic and spirochaetal infection were rare. The kidney changes possibly associated with leptospira infection have already been mentioned by Stevenson.

The other diseases encountered were pneumonia, cystic Fallopian tube, cystic kidney, cystic interstitial nephritis, vesical calculus, a condition in the spleen resembling actinomycosis, secondary septic infection of the lymphatic glands and various purulent infections of bacterial origin. 
No case of rat leprosy was encountered and the absence of neoplasms was rather surprising.

\section{MISCELLANY.}

Pregnancies appeared to be commonest from April to June, during which period 39.5 per cent. of female brown rats examined were pregnant. There seems to be a second breeding period from September to November. July and August appear to be off-seasons, as do the winter months from December to January inclusive. The numbers examined, however, were perhaps too small to allow any conclusions to be drawn.

\section{SUMMARY.}

1. Attempts to secure a micro-organism which could induce abortion or sterility in wild rats and which might be used in an anti-rat campaign, more especially when plague threatens a community, have not been successful.

2. An account, however, is given of certain micro-organisms producing pathological conditions in the genito-urinary tract of wild rats.

3. A routine determination of rat parasites including ecto-parasites, helminths, intestinal protozoa and haematozoa has been undertaken.

4. It has led to the discovery of a new species of Hymenolepis and has shown that Heligmosomum braziliense is present in rats in England. It has 'also demonstrated the occurrence of haemogregarines in the leucocytes of black rats in this country.

5. Work has been done on the incidence of Leptospira icterohaemorrhagiae in Rattus norvegicus and Rattus rattus in England and on the mechanism of its transmission.

6. It has been shown that apparently the guinea pig may act as a carrier of the Leptospira without exhibiting any marked symptoms of the disease which the latter produces. There is also some evidence to prove that infection may take place through the alimentary tract.

7. The Leptospira was successfully and easily cultivated in Wenyon's modification of the Noguchi method but in large measure lost its virulence as the result of repeated subcultures. Even after a year, however, it was still capable of producing characteristic symptoms in the guinea pig.

8. General pathological conditions occurring in wild rats have been recorded.

9. A few observations have been made on the seasonal incidence of pregnancy in wild rats.

\section{REFERENCES.}

BACot, A. W. (1919). The fleas found on rats and their relation to plague. Journ. Roy. Sanit. Inst. XL. 53.

Batfour, A. (14. v. 1921). Rat destruction: a suggestion. Lancet, I. 1049.

BAYLIS, H. A. (25. iv. 1922). Observations on certain cestodes of rats, with an account of a new specics of Hymenolepis. Parasitology, xiv. 1.

Brug, S. L. (1919). De Entamoeben van de rat. Geneesk. Tijdschr. Nederlandsch-Indië. uIv. Part 4. 
Chadssat, J. B. (1850). Recherches microscopiques appliqueés à la pathologie. Des hématozoaires. Thèse. $51 \mathrm{pp}$.

Cleland, J. Burton (1. v. 1918). Presidential Address to the Royal Society of New South Wales. Sydney.

Coles, A. C. (1918). A note on the occurrence of Spirochata icterohaemorrhagiae in the common rat in England. Lancet. 468.

Dudgenon, G. C. (25. iv. 1922). Occurrence of Heligmosomum braziliense Trav. in England. Parasitology, xIv. 13.

Foulerton, A. G. R. (10. iv. 1919). Report on the protozoal parasites of the rat with special reference to the occurrence of spirochaetal jaundice in man and to the London rat as a natural reservoir of Spirochaeta icterohaemorrhagiae. Corporation of London: Public Health Department.

HALL, M. C. (1916). Nematode parasites of mammals of the orders Rodentia, Lagomorpha and Hyracoidea. Proc. U.S National Museum, 30.

H.rsT, S. (1914). Preliminary list of the Acari oceurring on the brown rat (Mus norvegicus) in Great Britain with the description of a new species (Haemogamasus oudemansi). Bull. Entomol. Research. v. 119.

Martin, L. and Pettit, A. (1919). Spirochétose ictérohémorragique, 284 pp.

MoLL, A. M. (xii. 1917). Animal parasites of rats at Madison, Wisconsin. Journ. of Parasitol. IV. 89.

NewSTEad, R. and Evans, A. M. (1921). Report on rat-flea investigation. Annals of Tropical Medicine and Parasitology, xv. 287.

Nuttald, G. H. F. and Strickland, C (iv. 1913). Report on rat-fleas in Cambridgeshire Parasitology, vr. 2.

ShrPley, A. E. (1908). Rats and their parasites. Journ. Economic Biol. III. 61.

SPLENDORE, A. (29. vr. 1918). Studi nell' interesse di una lotta biologica contro le arvicole. Bollet. Ser. B., Ministero.di Agricoltura. Rome.

Stammers, G. E. F. (1920). Haemogregarines in black rats. Journ. Trop. Med. and Hygiene, XXIII. 298.

Stevenson, A. C. (i. 1922). The incidence of a Leptospira in the kidneys and of parasites in the intestines of one hundred wild rats examined in England. American Journ. Trop. Med. II. 77.

Strickland, C. and Merriman, G. (iv. 1913). Report on rat-fleas in Suffolk and North Essex. Parasitology, vi. 2.

Teacher, J. H. and Burton, J. A. G. (1914 and 1915). Infective abortion in guinea pigs. Journ. Pathol. and Bacteriol. Xv世r. 440, and xx. 14.

Uhlenfuth, P. and Zuflzer, M. (1921). Zur Epidemiologie der weilschen Krankheitzugleich ein Beitrag zur Frage der freilebenden Spirochäten (Icterogenes-ähnliche und andere). Centralbl. f. Bakteriol., etc., Orig. Lxxxv. Supplement, p. 141.

WENYON, C. M. (1921). [Demonstration of a simple culture medium for the cultivation of Leptospira and Protozoa.] Report of Laboratory Meeting. Trans. Roy. Soc. Tropic. Med. and Hygiene, xv. 153. 


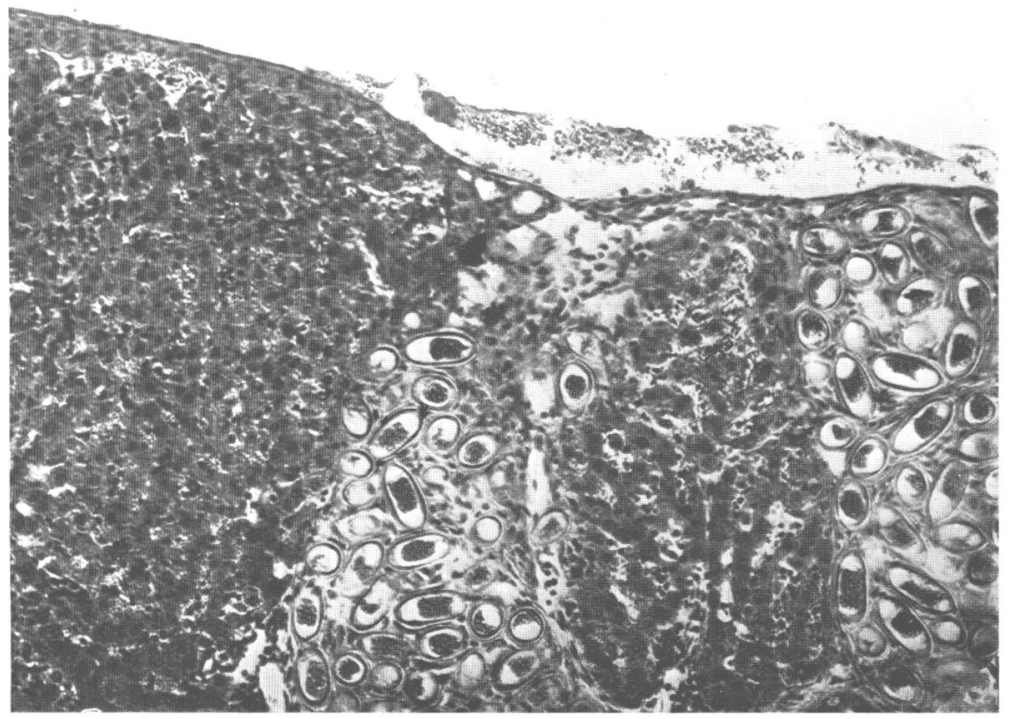

Fig. 1. Eggs of Hepaticola hepatica Hall in liver of rat. Note opercular plugs. $\times$ circa 350 diam.

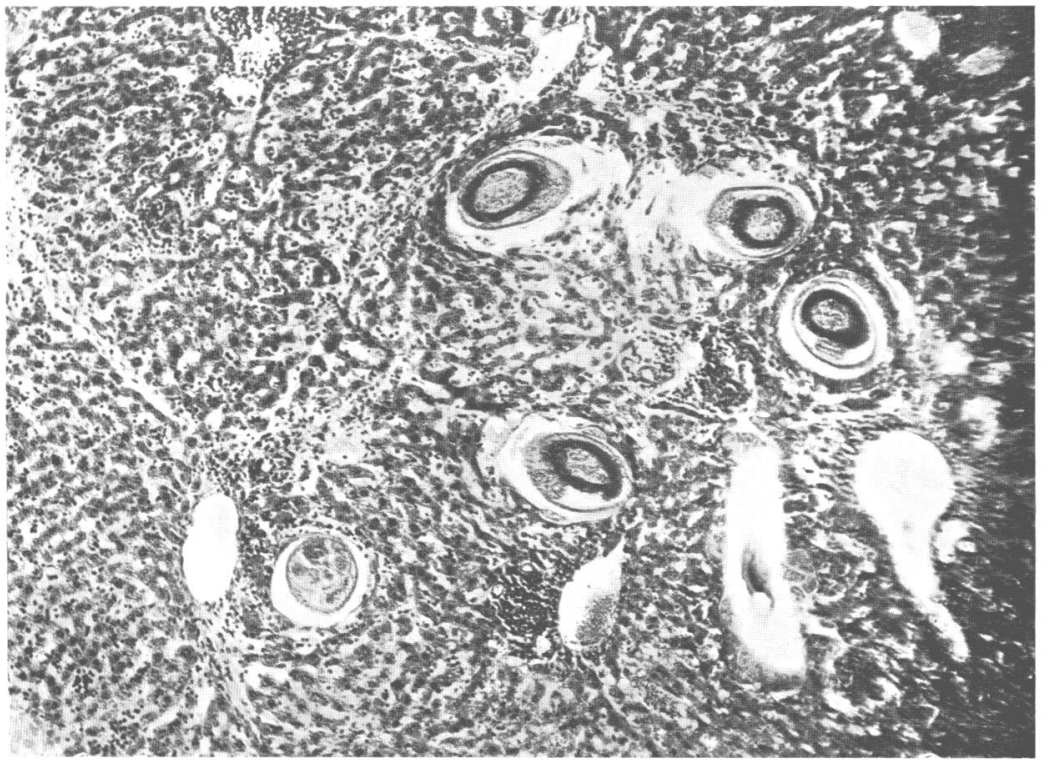

Fig. 2. Section of rat's liver showing cluster of sections of Hepaticola hepatica. $\times$ circa 85 diam. 
PARASITOLOGY, VOL, XIV. NOS. 3 AND 4

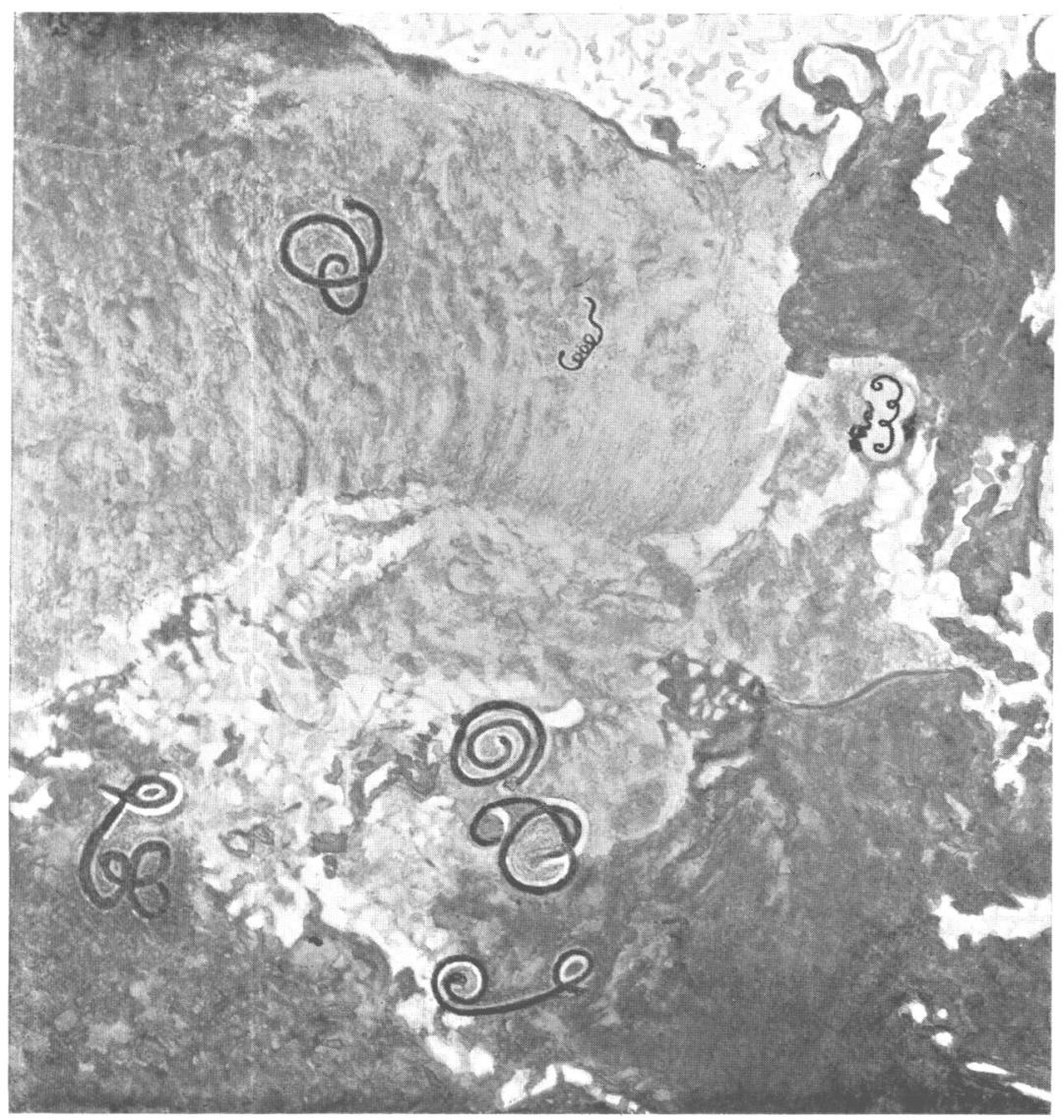

Fig. 3. Drawing made from photograph showing Heligmosomum braziliense in the intestinal mueus of a rat. The small forms may possibly be a species of Viannaia. $\times$ circa 12 diam. 